\title{
Elevated Fasting Blood Glucose is Associated with Increased Risk of Breast Cancer: Outcome of Case-control Study Conducted in Karachi, Pakistan
}

\author{
Syed Danish Haseen ${ }^{1 *}$, Aziza Khanam ${ }^{2}$, Naheed Sultan ${ }^{3}$, Farah Idrees ${ }^{3}$, Naheed \\ Akhtar $^{2}$, Fauzia Imtiaz
}

\begin{abstract}
Background: There are several validated risk factors for breast cancer. However the legitimacy of elevated fasting blood glucose (FBG) is not well established. This study was designed to assess this parameter as a risk factor for breast cancer among pre- and post-menopausal women. Materials and Methods: This case-control study was conducted at Department of Biochemistry, University of Karachi from June 2010 to August 2014. Simple random sampling technique was used to collect data of study subjects comprising 175 diagnosed breast cancer patients with positive histopathology from Breast Clinic, surgical unit-1, Civil Hospital, Karachi and 175 healthy controls from various screening programs. Blood samples were analyzed for FBG and serum insulin. Results: FBG, HOMA-IR, systolic and diastolic blood pressure were significantly raised in breast cancer cases when compared to control subjects. Cases and controls were further categorized in to two groups using cutoff value of $110 \mathrm{mg} / \mathrm{dl}$ to distinguish subjects into normal fasting glucose $(<110 \mathrm{mg} / \mathrm{dl})$ and having impaired fasting glucose $(\geq 110-\leq 125 \mathrm{mg} / \mathrm{dl})$ or diabetes $(\geq 126 \mathrm{mg} / \mathrm{dl})$. Odds ratios were found to be $1.57,2.15$ and 1.17 in overall, pre-menopausal and post-menopausal groups, respectively. (all $\mathbf{p}<0.05$ ). Conclusions: A statistically significant risk of breast cancer exists in women having elevated fasting blood glucose levels, corresponding to prediabetes and diabetes, among pre and postmenopausal ages, with comparatively greater effects in the premenopausal group.
\end{abstract}

Keywords: Breast cancer - glucose - prediabetes - diabetes mellitus - insulin - odds ratio - *MeSH

Asian Pac J Cancer Prev, 16 (2), 675-678

\section{Introduction}

In Pakistan breast cancer is the most common cancer among women. According to the cancer registry data in 2004, age-standardized (world) rate (ASR) of breast cancer in Karachi, Pakistan, was 69.1 per 100,000 per year and $34.6 \%$ frequency, which is the highest ASR reported for any Asian population (Bhurgri et al., 2004). The recent estimates of Breast Cancer in Pakistan were by Institute of Health Metrics and Evaluation (IHME), university of Washington are very alarming. Among South Asian countries, women living in Pakistan have the highest risk of developing breast cancer. In Pakistan, number of breast cancer cases in 1980 was 5567 that rose to 33415 in 2010 , similarly risk of incidence from 1 in 36 to 1 in 16 , and number of deaths 2497 to 9970 (IHME, 2011).

Breast cancer has no exact etiology, but it is a multifactorial disease that includes several risk factors. Some of the risk factors are western life style, family history, early menarche, late menopause, nulliparity, previous benign breast disease, and oral contraceptives, obesity, lack of breast-feeding, dietary fat and alcohol intake (McPherson et al., 2000). Breast cancer as a multifactorial disease shares common risk factors like sedentary life style, obesity and increase calorie intake with prediabetes and diabetes mellitus. Persistent hyperglycemia has been associated with increase risk of various cancers in men and women, including breast cancer (Czyzyk and Szczepanik, 2000; Strickler et al., 2001; Rapp et al., 2006; Yanget al., 2013; Tong et al., 2014). However elevated fasting blood glucose is not yet established as a recognized risk factor for breast cancer. A recent case-control study conducted on Malaysian population has demonstrated two times more risk of breast cancer in those women who consume higher amounts of added sugar (Sulaiman et al., 2014). Exact mechanism linking hyperglycemia with increased cancer risk is not yet known, though several hypotheses have been under debate. Persistent hyperglycemia which is more likely a result of insulin resistance among prediabetics and diabetics may provide a milieu for nurturing malignant cells (Warburg, 1956; Dang and Semenza, 1999). Insulin 
has also been indicted for its growth stimulating effects along hyperglycemia in various cancers including breast cancer (Ish-Shalom et al., 1997; Khandwala et al., 2000). Study conducted by Okumura et al. (2002) has demonstrated increased proliferation of breast cancer cells when subjected to elevated glucose concentration, linking the role of protein kinases and Peroxisome proliferatoractivated receptors. Another recent study (Anand et al., 2014) has found raised chromosomal abnormalities in diabetic subjects as compared to healthy controls, thus increasing he risk of cancer may be due to genomic instability.

Conflicting results have been achieved by studies (Manjer et al., 2001; Muti et al., 2002; Mink et al, 2002; Stattin et al., 2007; Kabat et al., 2009) that have attempted to determine the relationship of increased FBG with cancer. To our knowledge no similar study has been conducted in this region to establish elevated FBG as a risk factor for breast cancer.

\section{Materials and Methods}

This study was designed as a case-control study to identify the biochemical mechanisms in breast cancer patients in relation with metabolic dysregulation. It was conducted at Department of Biochemistry, University of Karachi from June 2010 to August 2014. Sample size was calculated by using frequency $(34.6 \%)$ of breast cancer in Pakistan indicated in a previous study (Bhurgri et al., 2004). Ethical approval was taken from the ethics and research committee of the Department of Biochemistry, University of Karachi. Simple random sampling technique was used to collect data of study subjects comprising cases (with disease) and controls (disease free) with their written informed consent. 175 diagnosed breast cancer patients with positive histopathology from Breast Clinic, Civil Hospital, Karachi and 175 controls from various screening programs were recruited for this study. Subjects undergone breast surgery, receiving chemotherapy or radiotherapy, on anti-estrogen drugs, hormones replacement therapy, contraceptive pills and subjects currently on insulin or anti diabetic treatment were excluded from the study.

Blood samples were obtained after an overnight fast by vein puncture under all aseptic measures. For premenopausal women blood samples were collected in the first week (early) of follicular phase of menstrual cycle to lower inconsistency among subjects. Serum was separated after clotting, centrifuged and stored at $-30^{\circ} \mathrm{C}$. Blood glucose was analyzed immediately using glucose oxidase kit provided by Merck, Germany, while serum insulin was analyzed later by DIAsource INS-EASIA Kit, Belgium.

Later data was entered and analyzed by using IBM SPSS 20 (IBM: 2011) statistical software and OpenEpi, Version 3, open source calculator (Dean et al., 2014). HOMA-IR was calculated by using the computer software HOMA2, an updated computer formula that considers changes in hepatic as well as peripheral glucose resistance (Levy et al., 1998). The odds ratio was estimated to find out the risk of breast cancer while using student t-test among case and control subjects compared mean values of basic demographic characteristics.

\section{Results}

A total of 350 subjects were selected. All the subjects were distributed into two groups, 175 cases suffering from breast cancer and their age, sex and BMI matched 175 controls healthy subjects. There were $39.4 \%$ premenopausal subjects among cases while $47.4 \%$ in control group. Similarly $60.5 \%$ postmenopausal were among cases while $52.5 \%$ were in control group. All IFG subjects and $60 \%$ of all diabetics were newly diagnosed.

Comparison of mean $( \pm$ sem) values of age, BMI, systolic and diastolic blood pressure, FBG, fasting serum insulin and HOMA-IR among case and control groups is represented in Table 1. FBG, HOMA-IR, systolic and diastolic blood pressure, were found to be significantly

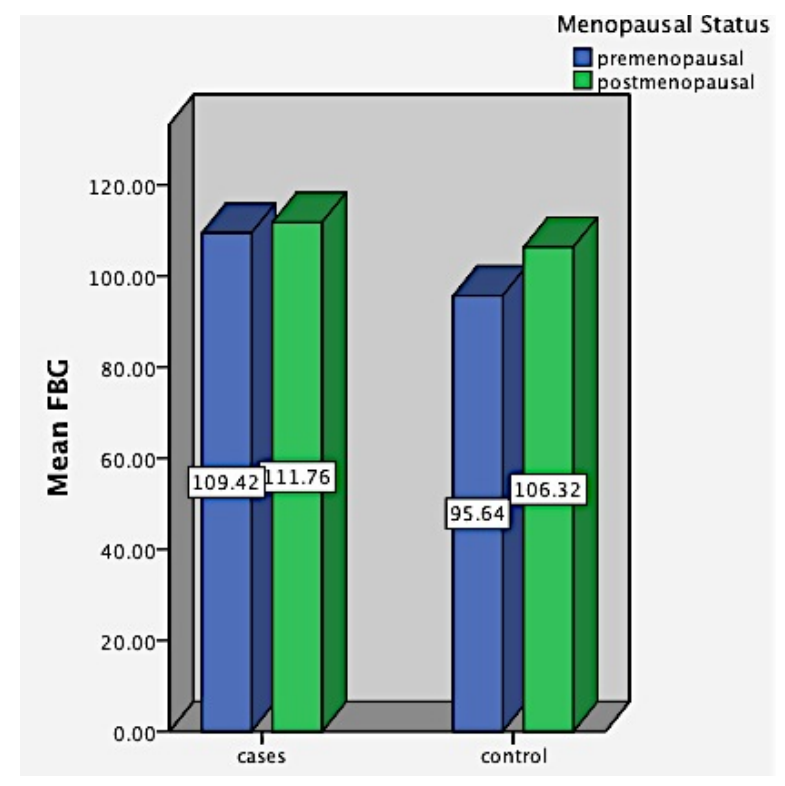

Figure 1. Comparison of FBG among Premenopausal and Postmenopausal Groups

Table 1. Clinical Characteristics of Breast Cancer Cases and Healthy Controls

\begin{tabular}{lrr}
\hline $\begin{array}{l}\text { Demographic Feature } \\
(\text { mean } \pm \text { SEM) }\end{array}$ & \multicolumn{1}{c}{$\begin{array}{c}\text { Cases } \\
(\text { mean } \pm \text { SEM) }\end{array}$} & Control \\
\hline Age $(\mathrm{yr})$ & $46.15 \pm 0.80$ & $44.52 \pm 0.80$ \\
BMI $\left(\mathrm{Kg} / \mathrm{m}^{2}\right)$ & $21.61 \pm 0.31$ & $21.60 \pm 0.28$ \\
Systolic Blood Pressure $(\mathrm{mmHg})$ & $127.25 \pm 1.45^{*}$ & $121.60 \pm 1.44$ \\
Diastolic Blood Pressure $(\mathrm{mmHg})$ & $81.00 \pm 0.69^{*}$ & $77.82 \pm 0.90$ \\
FBG (mg/dl) & $110.84 \pm 2.64^{*}$ & $101.25 \pm 2.64$ \\
Fasting Serum Insulin $(\mu \mathrm{IU} / \mathrm{ml})$ & $19.76 \pm 0.73^{*}$ & $15.41 \pm 0.61$ \\
HOMA-IR & $2.65 \pm 0.10^{*}$ & 0.070 \\
\hline
\end{tabular}


Table 2. Contingency Table For Calculating Risk of Breast Cancer in IFG Subjects

\begin{tabular}{|c|c|c|c|c|c|}
\hline \multirow[t]{2}{*}{ Breast Cancer } & \multicolumn{2}{|c|}{ FBG } & \multirow[t]{2}{*}{ Total } & \multirow[t]{2}{*}{ Odds Ratio } & \multirow[t]{2}{*}{$95 \% \mathrm{CI}$} \\
\hline & $\begin{array}{l}110 \mathrm{mg} / \mathrm{dl} \\
(\mathrm{IFG}+\mathrm{DM})\end{array}$ & $\begin{array}{c}<110 \mathrm{mg} / \mathrm{dl} \\
(\mathrm{NFG})\end{array}$ & & & \\
\hline \multicolumn{6}{|l|}{ Premenopausal } \\
\hline Case & 28 & 41 & 69 & $2.15^{*}$ & $1.073,4.313$ \\
\hline Control & 20 & 63 & 83 & & \\
\hline Total & 48 & 104 & 152 & & \\
\hline \multicolumn{6}{|l|}{ Postmenopausal } \\
\hline Case & 42 & 64 & 106 & $1.17 *$ & $0.6589,2.089$ \\
\hline Control & 33 & 59 & 92 & & \\
\hline Total & 75 & 123 & 198 & & \\
\hline \multicolumn{6}{|l|}{ Overall Subjects } \\
\hline Case & 71 & 104 & 175 & $1.57 *$ & $1.01-2.44 *$ \\
\hline Control & 53 & 122 & 175 & & \\
\hline Total & 124 & 226 & 350 & & \\
\hline
\end{tabular}

*IFG: impaired fasting glucose; DM: diabetes mellitus; NFG: normal fasting glucose; * significant values p<0.05

raised statistically in breast cancer cases when compared to control subjects. Figure 1 illustrates the comparison of mean FBG levels of pre and postmenopausal groups among cases and control. FBG was found significantly $(\mathrm{p}<0.05)$ higher in pre and postmenopausal cases when compared to healthy control.

Based on FBG levels, subjects were categorized according WHO (Alberti, 1998) criteria in to two groups using cutoff value of $110 \mathrm{mg} / \mathrm{dl}$ to distinguish subjects into NFG ( $<110 \mathrm{mg} / \mathrm{dl})$ and having IFG $(\geq 110-\leq 125 \mathrm{mg} / \mathrm{dl})$ or diabetes mellitus ( $\geq 126 \mathrm{mg} / \mathrm{dl}$ ). In premenopausal group odds ratio was calculated to be 2.15 , postmenopausal women OR was found to be 1.17 while OR among all ages was 1.57. All values were found to be statistically significant at $\mathrm{p}<0.05$.

\section{Discussion}

In this study, we have found higher levels of systolic and diastolic blood pressures, FBG, fasting serum insulin and HOMA-IR in breast cancer cases as compared to healthy controls. Other studies (Stattin et al., 2007; Kabat et al., 2009; Alokail et al., 2009; Sieri et al., 2012) have also found higher FBG, serum insulin and HOMA-IR in breast cancer cases when compared to healthy subjects, consistent with our results.

Results of previous studies that have attempted to associate elevated FBG levels with risk of breast cancer are conflicting and fluctuate with menopausal status. Studies published by Muti et al. (2002) and statin et al. (2007) have reported elevated blood glucose levels associated with significantly higher risk of breast cancer in premenopausal as compared with postmenopausal women having lower risk. While a study conducted with 77,228 women participants during a screening program in Austria has found elevated blood glucose associated with breast cancer risk, with greatest among those older than 65 years of age (Rapp et al., 2006). On the contrary, other studies (Manjer et al., 2001; Mink et al., 2002; Kabat et al., 2009) have found no association.

This study has demonstrated an overall 1.57 times risk (odds ratio) of developing breast cancer in women having elevated fating blood glucose levels when compared to
NGT, with greater in premenopausal $(\mathrm{OR}=2.15, \mathrm{p}<0.05)$ as compared to postmenopausal women $(\mathrm{OR}=1.17$, $\mathrm{p}<0.05)$. Higher risk of breast cancer in premenopausal as compared to postmenopausal women showed in this study is may represents different etiological factors like obesity, elevated serum insulin and estrogen concentrations behave reciprocally in these two menopausal states. However, in all three groups breast cancer risk emerged as greater since the the odds ratio was found statistically significant $(\mathrm{p}<0.05)$.

In conclusion, this study has demonstrated statistically significant higher risk of breast cancer in women having higher FBG levels corresponding to the IFG and diabetes mellitus among pre and postmenopausal ages. This has further validated the fact that higher FBG level signifies metabolic dysregulation and complex mechanism involved in breast carcinogenesis and thus indicates possible preventive measures.

Regarding strengths and limitations, the study has a case-control study design with a sample size estimated on the basis of prevalence in a previous study. This study has attained statistical power, however population based, multi-centric, prospective studies with repeated biochemical assays would be needed further establish teh external validity.

\section{Acknowledgements}

We would like to acknowledge patients and staff members of Breast Clinic, Surgical Unit-1, Civil Hospital Karachi, Pakistan.

\section{References}

Alberti KGMM, Zimmet PZ (1998). for the WHO Consultation: Definition, diagnosis and classification of diabetes mellitus and its complications. part 1: diagnosis and classification of diabetes mellitus, provisional report of a WHO consultation. Diabet Med, 15, 539-53.

Alokail MS, Al-Daghri NM, Al-Attas OS, Hussain T (2009). Combined effects of obesity and type 2 diabetes contribute to increased breast cancer risk in premenopausal women. Cardiovasc Diabetol, 8, 33.

Anand S, Nath B, Saraswathy R (2014). Diabetes-increased risk 
Syed Danish Haseen et al

for cancers through chromosomal aberrations? Asian Pac J Cancer Prev, 15, 4571.

Bhurgri Y (2004). Karachi cancer registry data--implications for the national cancer control program of pakistan. Asian Pac $J$ Cancer Prev, 5, 77-82.

Czyzyk A, Szczepanik Z (2000). Diabetes mellitus and cancer. Eur J Intern Med, 11, 245-52.

Dang CV, Semenza GL (1999). Oncogenic alterations of metabolism. Trends Biochem Sci, 24, 68-72.

Dean AG, Sullivan KM, Soe MM (2014). Openepi: open source epidemiologic statistics for public health, version. www. OpenEpi.com, updated 2014/09/01, accessed 2014/09/04.

IBM Corp. Released (2011). IBM SPSS Statistics for windows, version 20.0. Armonk, NY: IBM Corp.

Institute for Health Metrics and Evaluation (2011). The challenge ahead: progress and setbacks in breast and cervical cancer. seattle, WA: IHME.

Ish-Shalom D, Christoffersen CT, Vorwerk P et al (1997). Mitogenic properties of insulin and insulin analogues mediated by the insulin receptor. Diabetologia, 40, 25-31

Kabat GC, Kim M, Caan BJ, (2009). Repeated measures of serum glucose and insulin in relation to postmenopausal breast cancer. Int J Cancer, 125, 2704-10.

Khandwala HM, McCutcheon IE, Flyvbjerg A, Friend KE (2000). The effects of insulin-like growth factors on tumorigenesis and neoplastic growth. Endocr Rev, 21, 215-44.

Levy JC, Matthews DR, Hermans MP (1998). Correct homeostasis model assessment (HOMA) evaluation uses the computer program (Letter). Diabetes Care, 21, 2191-2.

Manjer J, Kaaks R, Riboli E, Berglund G (2001). Risk of breast cancer in relation to anthropometry, blood pressure, blood lipids and glucose metabolism: a prospective study within the malmo preventive project. Eur J Cancer Prev, 10, 33-42.

McPherson K, Steel C, Dixon JM (2000). ABC of breast diseases: breast cancer-epidemiology, risk factors, and genetics. British Medical J, 321, 624.

Mink PJ, Shahar E, Rosamond WD, Alberg AJ, Folsom AR (2002). Serum insulin and glucose levels and breast cancer incidence: the Atherosclerosis Risk in Communities Study. Am J Epidemiol, 156, 349-52.

Muti P, Quattrin T, Grant BJ, (2002). Fasting glucose is a risk factor for breast cancer: a prospective study. Cancer Epidemiol Biomarkers Prev, 11, 1361-8.

Okumura M, Yamamoto M, Sakuma H, (2002). Leptin and high glucose stimulate cell proliferation in MCF-7 human breast cancer cells: reciprocal involvement of PKC- $\alpha$ and PPAR expression. Biochim Biophys Acta, 1592, 107-16.

Rapp K, Schroeder J, Klenk J, (2006). FBG and cancer risk in a cohort of more than 140,000 adults in Austria. Diabetologia, 49, 945-52.

Sieri S, Muti P, Claudia A, (2012). Prospective study on the role of glucose metabolism in breast cancer occurrence. Int J Cancer, 130, 921-9.

Stattin P, Bjor O, Ferrari P, (2007). Prospective study of hyperglycemia and cancer risk. Diabetes Care, 30, 561-7.

Strickler HD, Wylie-Rosett J, Rohan T, (2001). The relation of type 2 diabetes and cancer. Diabetes Technol Ther, 3, 263-74.

Sulaiman S, Shahril MR, Wafa SW, Shaharudin SH, Hussin S (2014). Dietary carbohydrate, fiber and sugar and risk of breast cancer according to menopausal status in Malaysia. Asian Pac J Cancer Prev, 15, 5959.

Tong GX, Cheng J, Chai J, et al (2014). Association between gestational diabetes mellitus and subsequent risk of cancer: A systematic review of epidemiological studies. Asian Pac $J$ Cancer Prev, 15, 4265-9.

Warburg O (1956). On the origin of cancer cells. Science, 123, 309-14.
Yang XQ, Xu C, Sun Y, Han RF (2013). Diabetes mellitus increases the risk of bladder cancer: an updated metaanalysis. Asian Pac J Cancer Prev, 14, 2583-9. 